\title{
Effect of chewing gum on tooth sensitivity following whitening
}
IN BRIEF
- Reviews the prevalence and treatment options of whitening-induced tooth sensitivity.
- Reports that an in-office whitening procedure was effective in lightening the colour of teeth in one hour.
- Suggests that sugar-free chewing gum could be a useful adjunct for managing tooth sensitivity associated with
whitening procedures.

\author{
B. Tang ${ }^{1}$ and B. J. Millar ${ }^{2}$
}

\begin{abstract}
Objective Transient sensitivity is the most common side-effect associated with tooth whitening. The purpose of this randomised, controlled clinical study was to determine if a chewing gum containing Recaldent (CPP-ACP) was effective in reducing tooth sensitivity associated with in-office whitening procedures. Materials and methods Eighty-eight patients were recruited and had their teeth lightened using a single-visit, in-office whitening treatment with 15\% hydrogen peroxide augmented by light for a treatment period of one hour. Following the procedure, each patient was randomly assigned to one of three study groups: Group A, who used a sugar-free chewing gum with CPP-ACP; Group B, who did not use any desensitising agent; and Group C, who used a sugar-free chewing gum without CPP-ACP. The participants were requested to return for a 24 hour follow-up visit, at which the colour changes were measured using a value-oriented Vita classic shade guide. They also reported on the incidence, duration and intensity of tooth sensitivity experienced by completing a post-treatment questionnaire. Results The average Vita shade unit reduction was 4.8 and $88.6 \%$ of the patients were satisfied with their treatment outcomes. However, $85.2 \%$ of them experienced tooth sensitivity at some point following the whitening procedures. Both Group A and Group C experienced significantly less intense tooth sensitivity than Group B following the whitening procedures. However, Group A did not have a statistically significant reduction in the incidence, duration or intensity of sensitivity when compared to Group C. All sensitivity ceased at the 24 hour follow-up visits. Conclusion This study suggested that using a sugar-free chewing gum (both with and without CPP-ACP) could reduce the intensity of tooth sensitivity associated with in-office whitening procedures. However, it failed to demonstrate conclusively that using a sugar-free chewing gum with CPP-ACP could provide additional therapeutic benefits.
\end{abstract}

\section{INTRODUCTION}

The demand for tooth whitening has existed for more than 130 years, with the management of discoloured dentition first reported in $1877 .{ }^{1}$ Teeth discolour due to the effects of ageing, chromogenic foods, dental restorations, tetracycline use, fluorosis and/or the use of tobacco products. ${ }^{2}$ Today, tooth whitening has become the most popular elective procedure in dentistry, as it is a simple and non-invasive approach to cosmetically enhance one's appearance.

\footnotetext{
'Dental Practitioner, California, USA; ${ }^{2 *}$ Professor, Consultant in Restorative Dentistry, Director of Distance Learning, Department of Primary Care Dentistry, King's College London Dental Institute, Denmark Hill Campus, Bessemer Road, London, SE5 9RW, UK

${ }^{*}$ Correspondence to: Professor Brian Millar

Tel: +44 (0)20 7346 3585; Fax: +44 (0)207346 3826 Email:brian.millar@kcl.ac.uk
}

\section{Refereed Paper}

Accepted 25 March 2010

DOI: 10.1038/sj.bdj.2010.500

${ }^{\circledR}$ British Dental Journal 2010; 208: 571-577
Tooth whitening supervised by a dentist can be delivered through at-home tray bleaching or in-office procedures. In-office tooth whitening was developed to accelerate the bleaching process and allow the dentist to have direct control over the procedure. It provides immediate results for patients who lack the compliance to undertake at-home tray bleaching. Today, in-office whitening procedures that utilise hydrogen peroxide solutions as the bleaching agent and a heat or light source for activation have documented effectiveness and safety. ${ }^{3-6}$

One popular in-office system that has been clinically evaluated is the Britesmile tooth whitening system. ${ }^{7,8}$ The Britesmile system uses a 15\% hydrogen peroxide gel in combination with a blue LED light to whiten all of the smile-line teeth in one hour. Characteristics of the Britesmile system include rapid whitening, relatively low-concentration hydrogen peroxide, and less pain-inducing application. ${ }^{9}$ In a recent study, Tavares reported that using the Britesmile system with both peroxide and light treatment significantly lightened the colour of teeth. ${ }^{8}$ However, a recent systematic review noted that controversy still persists as to the role of a light in tooth whitening. ${ }^{10}$

Tooth sensitivity has been recognised as a common side-effect of all peroxidebased whitening procedures. ${ }^{11}$ Although the aetiology of tooth sensitivity is not completely understood, it has been demonstrated that peroxide penetrates through the tooth to the pulp in minutes and can cause a mild inflammatory response of the pulp. ${ }^{12}$ This could result in tooth sensitivity, but if the pulp remains healthy the sensitivity is usually reversible. It has also been suggested that stain removal could open dentinal tubules and increase tooth sensitivity. ${ }^{13}$ This explanation is consistent with Brannstrom's hydrodynamic theory, 
which proposed that the movement of fluid within the dentinal tubules could elicit a painful response. ${ }^{14}$

Numerous desensitising agents have been developed to manage tooth sensitivity, with varying reported success. Fluoride application has traditionally been used to manage sensitivity and is thought to act as a tubule blocker to control pulpal fluid flow. ${ }^{15}$ Potassium nitrate $5 \%$ has also been shown to be an effective desensitiser in toothpaste if used in a regular regimen. ${ }^{16}$ Potassium nitrate penetrates the tooth and is thought to have a calming effect on the nerve by preventing the nerve from repolarising after it has depolarised in the pain cycle. ${ }^{17}$

More recently, an effective carrier for calcium and phosphate called Recaldent (CPP-ACP) has been developed. ${ }^{18}$ Recaldent contains the milk-derived protein casein phosphopeptide (CPP), which carries calcium and phosphate ions in the form of amorphous calcium phosphate (ACP). Calcium phosphate is normally insoluble at neutral $\mathrm{pH}$, however the CPP keeps the calcium and phosphate in an amorphous non-crystalline state. When CPP-ACP is added to the oral cavity, the sticky CPP part bonds readily to the biofilms and surrounding oral tissue, leaving calcium and phosphate in high concentrations at the tooth surface to effect remineralisation. ${ }^{19}$

Studies have shown that Recaldent is effective in preventing and reversing early caries..$^{20}$ Following whitening procedures, the application of Recaldent might also provide a rapid desensitising effect through rapid protein binding deposition of calcium and phosphate ions within the exposed dentinal tubules. ${ }^{21}$ Recaldent was first introduced in the United States as a water-based topical paste (MI paste by GC America). Recently, a chewing gum with Recaldent has also become available (Trident White by Cadbury Adams), and has been found to increase tooth remineralisation above that which occurred with salivary stimulation from chewing regular sugar-free gums. ${ }^{22}$ However, to date the effect of chewing Recaldent-containing gum on reducing whitening-induced tooth sensitivity has not yet been explored.

The aim of this randomised, controlled clinical study was to determine if Recaldent (CPP-ACP) delivered in the form of a sugar-free chewing gum could

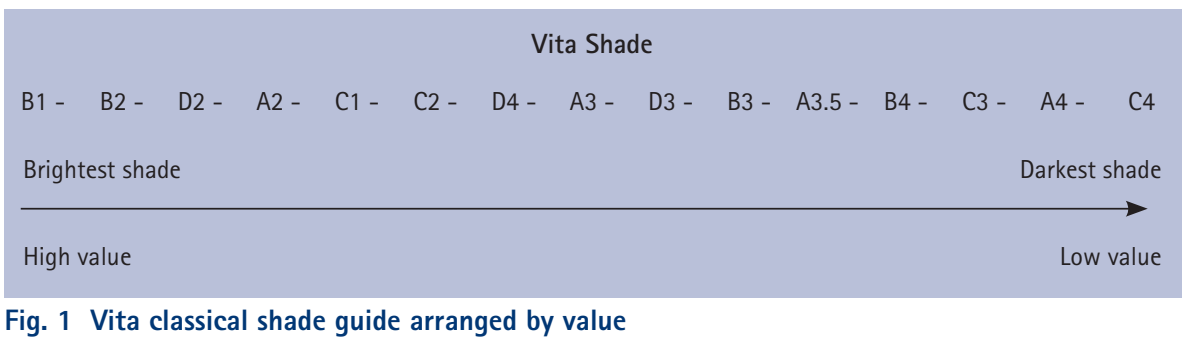

\section{4-HOUR POST-WHITENING QUESTIONNAIRE}

Please fill out the following questionnaire carefully. Thank you for your invaluable feedback!

Are you satisfied with the whitening result (tick one)? $\otimes$ Yes $\otimes$ No

If no, please explain briefly:

Did you experience any teeth sensitivity after the whitening procedure (tick one)? $\nabla$ Yes $\nabla$ No

If teeth sensitivity was present, how long did it last (in hours)?

If teeth sensitivity was present, on average how intense was the pain (circle level on scale)?

$\begin{array}{lllllrrrrrr}0 & 1 & 2 & 3 & 4 & 5 & 6 & 7 & 8 & 9 & 10 \\ \text { No pain } & & & & & \\ \text { Moderate pain } & & & & & \text { Worst possible pain }\end{array}$

Did you use anything to help alleviate the pain (tick all that apply)?

None $\mathbb{B}$

Sugar-free chewing gums provided by study $\mathbb{\Delta}$

Other topical agents or drugs (please specify):

Code Number:

Fig. 2 Sample 24 hour post-treatment questionnaire

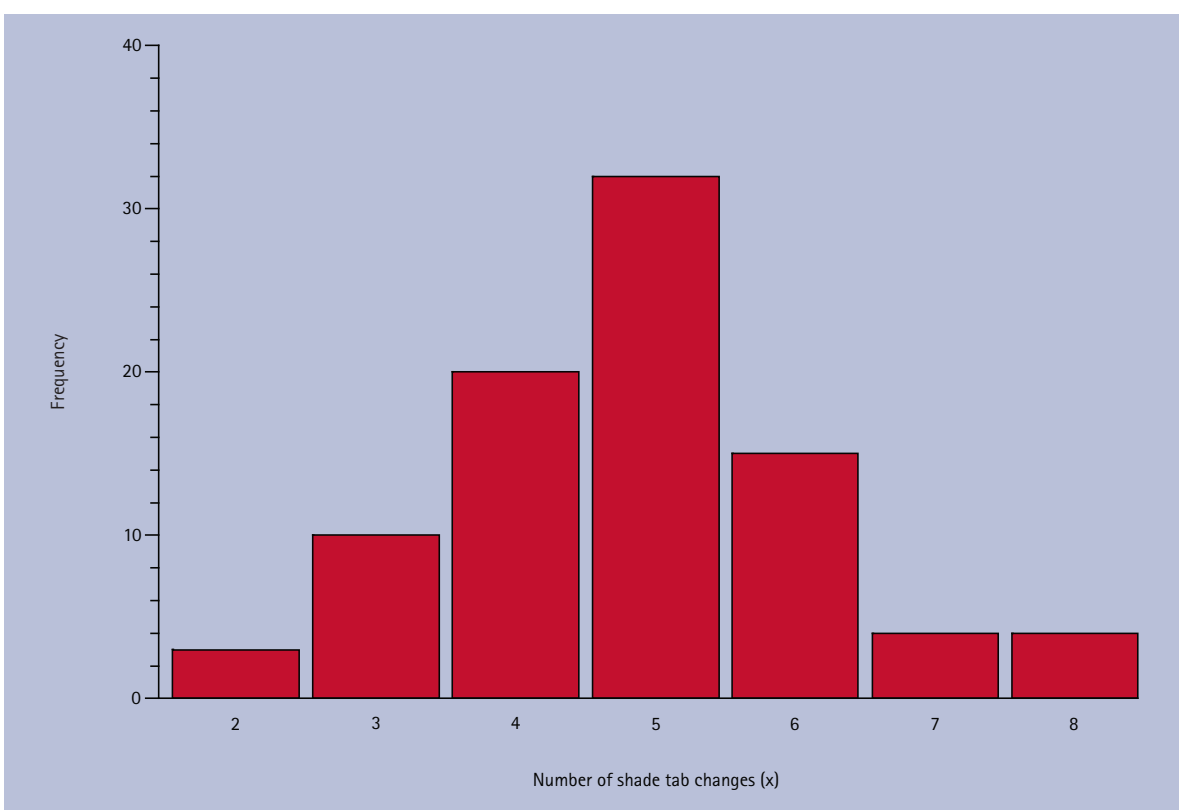

Fig. 3 Shade tab changes of in-office tooth whitening patients $(n=88)$

significantly reduce the incidence, duration and intensity of whitening-induced tooth sensitivity associated with the Britesmile procedure. The outcome of this study might provide supporting evidence for a simple and cost-effective treatment modality that could enhance patients' comfort in the future.

\section{MATERIALS AND METHODS}

\section{Subject recruitment process}

This study was approved by the Copernicus Group Independent Review Board on 11 January 2008. All subjects were recruited in a private clinic located in Mountain View, CA, USA subsequent to the study 
approval. The recruiting process involved using the committee-approved recruiting script to recruit consecutive patients who required tooth whitening and who fulfilled the inclusion criteria. A pilot study was completed in which three out of ten subjects experienced moderate sensitivity following the in-office whitening procedures. Based on sample size calculation using the Altman's nomogram, a sample size of approximately 120 was determined. ${ }^{23}$

Inclusion criteria included good general health and age between 18 and 65 years. Study subjects needed to have a minimum of 20 teeth, no prior history of tooth sensitivity and no extensive restorations. Exclusion criteria included pregnancy, breast-feeding, whitening performed within the last six months, untreated oral diseases and patients with milk protein allergy. All subjects also had to sign committee-approved informed consent forms.

\section{Study design and conduct}

Tooth whitening was performed on each participant using the standard Britesmile procedure as follows:

1. Pre-treatment tooth colour was measured using a value-oriented Vitapan shade guide and an initial photograph of the upper and lower teeth taken

2. The patient brushed his/her teeth with a pre-whitening toothpaste to remove loose debris and stain

3. A cheek retractor was placed to expose all smile-line teeth and cotton rolls were placed in the cheek vestibules to control saliva build-up

4. The patient bit down on a special optic positioning device as a jaw rest

5. A light-cured resin barrier material was placed on the exposed gingiva to protect the soft tissues

6. Both the subject and operator wore orange-tinted protective eyewear. Additional protective barriers were placed on the patient

7. A $15 \%$ hydrogen peroxide gel was placed evenly onto the buccal surfaces of all teeth in the smile zone

8. The teeth were illuminated with the blue LED light for 20 minutes. The light was positioned using the integral optic positioning device

9. The above two steps were repeated for a total exposure time of one hour
10. The gel was suctioned off after the procedure, and the cheek retractor and other protective barriers were removed

11. The patient brushed and rinsed to remove any residual gel.

Following the whitening procedure, each patient was given detailed post-treatment instructions. He/she was also instructed to avoid using any desensitising agents not specifically prescribed by the investigator if some sensitivity symptoms occurred. The patient was then randomly allocated to one of three study groups using the blocked randomisation method to achieve approximately equal numbers in each group. ${ }^{24}$ The three groups were as follows:

- Group A (experimental group) recommended to use a sugar-free chewing gum with Recaldent (Trident White by Cadbury Adams). The gum was provided in an unlabelled package of 12 and was wrapped identically to the other test gum in order to blind the study. Each patient was instructed to chew one piece of gum for 10 minutes every hour until the whole package was consumed

- Group B (control group \#1) - no treatment for tooth sensitivity was recommended

- Group C (control group \#2) recommended to use a sugar-free chewing gum without Recaldent (Orbit by Wrigley). The gum was provided in an unlabelled package of 12 and was wrapped identically to the other test gum in order to blind the study. Each of the patient was instructed to chew one piece of gum for 10 minutes every hour until the whole package was consumed.

\section{Methods of data collection and statistical analysis}

Study subjects returned for a followup visit 24 hours after the procedure to have their post-treatment shade recorded. A Vitapan shade guide was used by the investigator for subjective assessment of the shades. The shade changes were determined by counting the change in number of shade units that occurred towards the lighter end of the value-oriented shade guide (Fig. 1). This method was employed in several whitening studies and has been acknowledged to yield clinically relevant results, since successful whitening calls for a perceivable change in tooth colour. ${ }^{25} \mathrm{~A}$ final photograph was then taken of the upper and lower teeth.

Each patient also completed a 24 hour post-whitening questionnaire describing the incidence, duration and intensity of his/ her post-treatment sensitivity (Fig. 2). Each question of the questionnaire was aimed at eliciting specific information as follows:

1. Responses for question \# 1 would help determine whether in-office tooth whitening using the Britesmile system was, in general, an effective and satisfactory treatment modality

2. Responses for question \#2 would help determine the percentage of subjects who experienced post-treatment sensitivity

3. Question \#3 would help determine the duration of sensitivity that a subject experienced (in hours)

4. Question \#4 would help determine the intensity of sensitivity that a subject experienced (based on a self-reported level of pain on a scale of 0 to 10)

5. Question \#5 would identify the desensitising agent (if any) that a subject used to help alleviate the posttreatment sensitivity. Confounding data from subjects who used desensitising agents not specifically prescribed by the investigator (question 5c) would also be identified and excluded from the study.

After data collection was completed, the code was broken and the investigator identified the type of desensitising agent (if any) that a particular subject used following the whitening procedure. Descriptive statistics was carried out to analyse and summarise the data. Using the StatsDirect software (version 2.6.8), statistical testing was also performed to test the null hypothesis that any differences in pain perception (incidence, duration or intensity) between the three study groups were solely due to sampling error. Statistical testing was carried out using the chi-square, one-way ANOVA or Kruskal-Wallis test as appropriate.

\section{RESULTS}

\section{Characteristics of the study subjects}

Between January 2008 and July 2008, 96 patients were initially recruited to participate in the study: 51 women and 45 men, 
ranging from 22 to 58 years of age with an average age of 36.7 years. All subjects returned in 24 hours for the completion of a post-whitening questionnaire. They were randomly assigned to the three study groups using the blocked randomisation method to achieve equal numbers in each group (32). However, eight of them were subsequently excluded from the analysis because of ineligibility due to the use of desensitising agents not specifically prescribed by the investigator. The final number of subjects included in the analysis was 88, with 30 subjects in Group A, 30 subjects in Group B and 28 subjects in Group C.

\section{Efficacy of the Britesmile tooth whitening procedure}

The recorded shades using the Vitapan shade guide showed that the median number of shade tab changes was 5 tabs. The smallest change was 2 tabs, and the largest was 8 tabs. Since the number of shade tab changes was a qualitative ordinal variable it could be summarised using a bar graph (Fig. 3).

\section{Level of patient satisfaction}

Seventy-eight of the 88 participants (88.6\%) reported satisfaction with their whitening results. However, ten of the participants (11.4\%) were dissatisfied with their treatment results and the specific reasons for dissatisfaction cited included insufficient shade improvement (four responses), rapid shade relapse (three responses), uneven/ patchy colour (two responses) and no noticeable colour change (one response).

\section{Incidence of tooth sensitivity}

Seventy-five of the 88 participants (85.2\%) reported sensitivity at some point following the whitening procedures. The incidence of sensitivity appeared to be similar among the three study groups: 25 of the 30 participants (83.3\%) in Group A, 26 of the 30 participants (86.7\%) in Group B, and 24 of the 28 participants (85.7\%) in Group C. The chi-square test was used to test the null hypothesis that the population proportion of patients who experienced tooth sensitivity was equal among the three groups (Table 1). The calculated $\mathrm{p}$-value $(\mathrm{p}>0.05)$ provided no clear evidence against the null hypothesis, suggesting that there was no significant difference

Table 1 Chi-square test for incidence of sensitivity following in-office tooth whitening procedures

\begin{tabular}{|c|c|c|c|c|c|}
\hline & & Sensitivity + & Sensitivity - & Total & Percent \\
\hline \multirow{2}{*}{ Group A } & Observed & 25 & 5 & \multirow{2}{*}{30} & \multirow{2}{*}{83.33} \\
\hline & Expected & 25.57 & 4.43 & & \\
\hline \multirow{2}{*}{ Group B } & Observed & 26 & 4 & \multirow{2}{*}{30} & \multirow{2}{*}{86.67} \\
\hline & Expected & 25.57 & 4.43 & & \\
\hline \multirow{2}{*}{ Group C } & Observed & 24 & 4 & \multirow{2}{*}{28} & \multirow{2}{*}{85.71} \\
\hline & Expected & 23.86 & 4.14 & & \\
\hline
\end{tabular}

Table 2 ANOVA test for duration of sensitivity following in-office tooth whitening procedures

\begin{tabular}{|c|c|c|c|c|c|c|c|c|}
\hline \multirow{2}{*}{ Variable } & \multirow{2}{*}{$\mathrm{N}$} & \multirow{2}{*}{ Mean } & \multirow{2}{*}{$\begin{array}{l}\text { Standard } \\
\text { deviation }\end{array}$} & \multirow{2}{*}{$\begin{array}{l}\text { Standard } \\
\text { error }\end{array}$} & \multicolumn{2}{|c|}{$95 \% \mathrm{Cl}$ for mean } & \multirow{2}{*}{ Min } & \multirow{2}{*}{ Max } \\
\hline & & & & & Upper & Lower & & \\
\hline Duration A & 30 & 4.8 & 3.4 & 0.6 & 3.5 & 6.1 & 0 & 12 \\
\hline Duration B & 30 & 4.9 & 3.2 & 0.6 & 3.7 & 6.1 & 0 & 12 \\
\hline Duration C & 28 & 5.1 & 3.5 & 0.7 & 3.8 & 6.5 & 0 & 12 \\
\hline \multicolumn{9}{|c|}{ Variables: Duration A, Duration B, Duration C } \\
\hline \multicolumn{2}{|c|}{ Source of variation } & \multicolumn{2}{|c|}{ Sum squares } & \multicolumn{2}{|l|}{$\mathrm{DF}$} & & \multicolumn{2}{|c|}{ Mean square } \\
\hline \multicolumn{2}{|c|}{ Between groups } & \multicolumn{2}{|l|}{1.79} & \multicolumn{2}{|l|}{2} & & \multicolumn{2}{|l|}{0.89} \\
\hline \multicolumn{2}{|c|}{ Within groups } & \multicolumn{2}{|c|}{960.93} & \multicolumn{2}{|l|}{85} & & \multicolumn{2}{|l|}{11.31} \\
\hline \multicolumn{2}{|c|}{ Corrected total } & \multicolumn{2}{|c|}{962.72} & \multicolumn{2}{|l|}{87} & & & \\
\hline
\end{tabular}

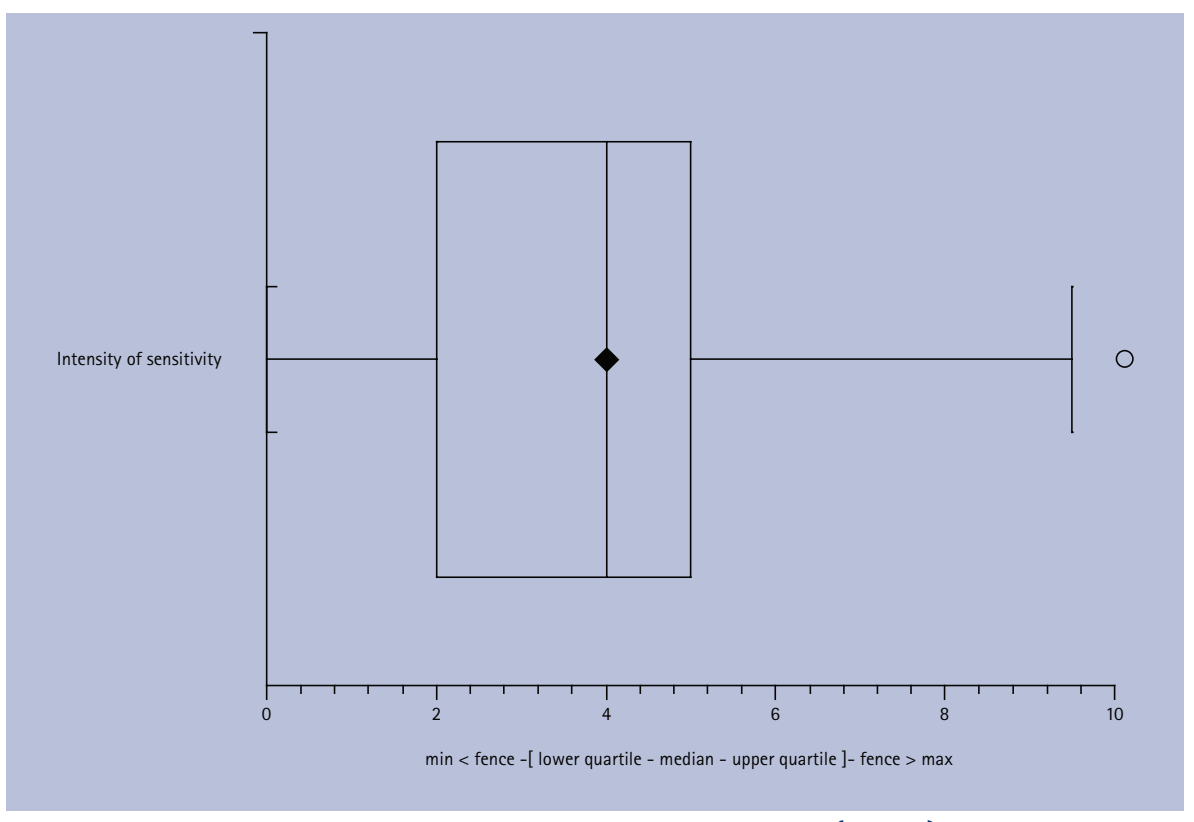

Fig. 4 Intensity of sensitivity of in-office tooth whitening patients $(n=88)$

in the incidence of sensitivity between the three study groups.

\section{Duration of tooth sensitivity}

The subjects reported a mean duration of sensitivity of 4.9 hours with a standard deviation of 3.3 and a 95\% confidence interval of 4.2 to 5.6. Assuming the data distribution was approximately normal, the parametric one-way ANOVA test was 
used to test the null hypothesis that all three groups came from populations with the same mean duration of sensitivity (Table 2). The calculated $p$-value $(p>0.05)$ provided no clear evidence against the null hypothesis, suggesting that there was no significant difference in the duration of sensitivity between the three study groups.

\section{Intensity of tooth sensitivity}

Overall the subjects reported a median intensity of sensitivity of 4 on a scale of 0 to $10(0=$ none, $10=$ worst $)$. Since the intensity of sensitivity was a qualitative ordinal variable, a box and whisker plot could be used to summarise the median, range, interquartile range and outliers of this data set (Fig. 4).

The plots of the three study groups could also be put together side-by-side for comparison (Fig. 5). The intensity of sensitivity appeared to differ significantly between the groups. The non-parametric Kruskal-Wallis test was used to test the null hypothesis that the observations from one group did not tend to yield higher or lower values than those from the other two groups (Table 3). Since the test result was highly significant ( $p=0.013$ ), we could reject the null hypothesis and assume that at least one of the sample populations tended to yield larger observations than at least one other sample population.

Multiple comparisons between the samples were necessary to determine where the differences lay. Two multiple comparison tests were used to make all possible pairwise comparisons between the groups, including Dwass-Steel-Chritchlow-Fligner (Table 4) and Conover-Inman (Table 5). Both tests indicated a significant difference $(p<0.05)$ in intensity of sensitivity between Group B and the other two groups. However, no statistical significance was detected between Group A and Group C.

\section{DISCUSSION}

The participants in this study were able to tolerate the procedure well, as 100\% of them were able to complete the treatment and return for a 24 hour follow-up visit. Most of them (88.6\%) were also satisfied with the treatment outcome. Our patients had a significant average shade improvement of 4.8. Such results confirmed

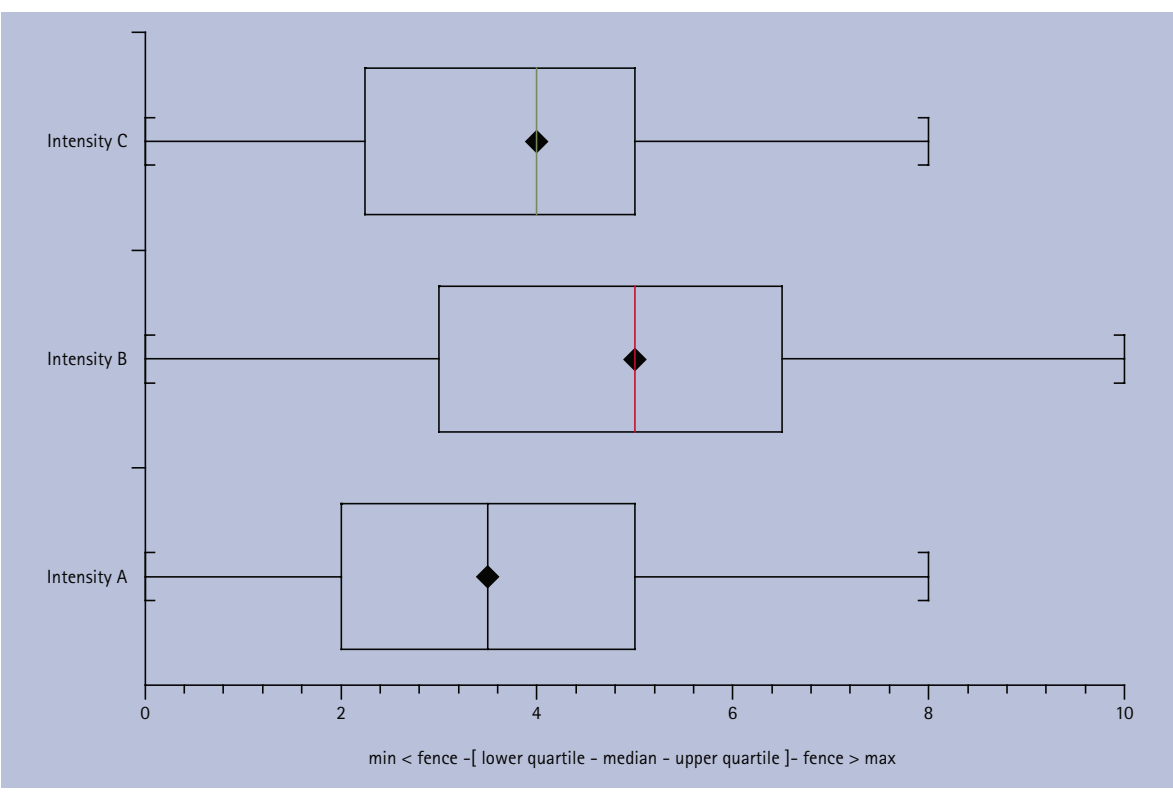

Fig. 5 Comparison of intensity of sensitivity for the three study groups

Table 3 Kruskal-Wallis test for intensity of pain following in-office tooth whitening procedures

Variables: Intensity A, Intensity B, Intensity C

\begin{tabular}{l|l}
\hline Groups & 3 \\
\hline Degrees of freedom & 2 \\
\hline Total observations & 88 \\
\hline$T$ & 8.53 \\
\hline$p$ & 0.014 \\
\hline Adjusted for ties: & \\
\hline$T$ & 8.74 \\
\hline$p$ & 0.013
\end{tabular}

Table 4 Kruskal-Wallis: all pairwise comparisons (Dwass-Steel-Chritchlow-Fligner)

Critical q (range) $=3.31$

Intensity A vs Intensity B $(|3.70|>3.31)$

Intensity A vs Intensity C $(|0.64|>3.31)$

Intensity B vs Intensity C $(|-3.44|>3.31)$

\section{Table 5 Kruskal-Wallis: all pairwise comparisons (Conover-Inman)}

Critical t (85 DF) = 1.99

Intensity A and Intensity B

$(17.77>12.60)$

Intensity A and Intensity C

$(2.28>12.82)$

Intensity B and Intensity C

(15.48 > 12.82)

the experience of the authors that the Britesmile system was indeed effective in whitening teeth in a single visit.
Significant

$p=0.02$

Not significant $p=0.89$

Significant $p=0.04$
However, the majority of the participants (85.2\%) reported sensitivity following the whitening procedures. Our result 
was consistent with other studies' findings that the incidence of sensitivity was high following any peroxide-based whitening procedures. Haywood, in a review of at-home tray bleaching, estimated that sensitivity was a problem for two out of three people. ${ }^{26}$ Schulte found that sensitivity was severe enough to cause $14 \%$ of study participants to discontinue bleaching. ${ }^{27}$ Sulieman further commented that the sensitivity issue has attracted little research attention, even though a majority of patients experience sensitivity during bleaching. ${ }^{28}$

On average, the sensitivity experienced by our subjects was relatively short-lived, with a mean of 4.9 hours and a range of 0 to 12 hours. Our data demonstrated that the duration of sensitivity varied greatly from participant to participant, but the sensitivity was transient as none of our subjects complained of lingering discomfort. Other clinical studies have also found that whitening-induced tooth sensitivity was usually temporary with no long-term adverse effects. ${ }^{29}$ Hewlett commented that although the sensitivity was usually transient, it could still render tooth whitening unavailable to patients who experienced severe hypersensitivity during the procedure. ${ }^{30}$

The intensity of sensitivity also varied greatly among our subjects. Based on a subjective self-assessment of unstimulated tooth sensitivity on a scale of 0 to 10 , our study group as a whole reported a median level of intensity of 4 with a range of 0 to 10. According to Kingdon, such numerical rating scales that allow the patient to mark the number that corresponds to the pain intensity are intuitive and effective. ${ }^{31}$ Most previous studies have also used similar self-assessment scales for measuring intensity of pain induced by tooth whitening procedures. ${ }^{32-34}$ However, given the differences in the way data were collected and the whitening system used, comparison to other studies was not possible.

Further comparison of our three study groups revealed some interesting observations. The median intensity of sensitivity was notably higher among the subjects who did not use any desensitising agent (Group B) when compared to the other two groups who used sugar-free chewing gums (Group A and Group C). Using multiple comparison tests we did confirm that the difference between Group B and the other two groups was statistically significant; however, we failed to show a significant difference in sensitivity between Group A and Group C. Our results strongly suggested that using either of the sugar-free chewing gums as directed could help reduce the intensity of tooth sensitivity.

Several theories could help explain why both groups of gum users experienced less sensitivity. First, the reduction in sensitivity might be just a placebo response. In general, a large placebo effect has been measured in tooth sensitivity studies, making assessment of efficacy difficult. Curro reviewed the placebo-induced sensitivity reduction that was measured in a number of tooth sensitivity clinical trials. ${ }^{35}$ It was observed that placebo-induced pain reductions in the 30-40\% range were often seen in these studies. Such a magnitude of placebo-induced pain reduction was reasonable as it did not exceed those observed in clinical trials of some analgesic drugs. ${ }^{36}$

Another explanation could be that the distraction associated with gum chewing might provide some actual therapeutic effect above and beyond the placebo effect. As a result of the strong psychological component of pain perception, supplemental use of non-pharmacological analgesic techniques can sometimes be effective. In a meta-analysis, cognitive-behavioural strategies have been found to result in significantly reduced pain reported in 85\% of 47 studies. $^{37}$ McCaul suggested that distraction was a cognitive-behavioural intervention particularly useful for mild to moderate pain..$^{38}$ The action of chewing gum might therefore provide a soothing distraction to get the patient's mind off the tooth sensitivity.

Chewing gum could also increase stimulated salivary flow that might help reduce whitening-induced tooth sensitivity. It is well documented that gum chewing can stimulate salivary flow and reduce the incidence of dental caries. ${ }^{39}$ Studies also show that stimulating the flow of saliva alters its composition. Dawes noted that increasing the rate of salivary flow increased the concentration of protein, sodium, chloride and bicarbonate..$^{40}$ The increased concentration of bicarbonate favoured the remineralisation of damaged enamel and dentine. Such remineralisation processes might also help occlude open tubules to reduce dentinal hypersensitivity. However, the ability of this remineralisation to treat sensitivity has yet to be demonstrated.

In summary, this study suggested that using a sugar-free chewing gum might help reduce the intensity of whitening-induced tooth sensitivity. However, it was unable to provide conclusive evidence that using a Recaldent-containing gum has any additional therapeutic benefits. The difference might simply be too small to demonstrate statistical significance. Several limitations of this study might have also compromised our ability to detect a significant difference between our study groups.

One of the major shortcomings of this study was its relatively small sample size. Originally a sample size of approximately 120 was deemed appropriate. However, due to the time constraint of this study only 88 subjects were recruited for the final analysis. In general, larger samples provide greater statistical power to detect any real treatment difference, if one exists. ${ }^{41}$ For this study a larger sample was particularly important because tooth sensitivity is a subjective sensation that is difficult to quantify precisely. Other studies on tooth sensitivity found that larger sample sizes were needed to overcome measurement inaccuracies between patients and observers. ${ }^{42-44}$ Future studies should therefore collect larger samples to better detect a smaller real difference as significant between the study groups.

Another limitation of this study was the lack of long-term follow-up on the subjects. Again, this was due to the time constraint of this investigation. Although tooth sensitivity reported in this study was short-lived, as none of our subjects had lingering discomfort at the followup visits, some investigators have found that sensitivity can last up to six months following a single episode of bleaching. ${ }^{8}$ Future studies should therefore arrange for additional follow-up appointments to reevaluate the subjects' pain experience and detect any outcome difference among the study groups.

Lack of benefit for the experimental group (Group A) could also be attributed to the relatively low concentration of CPP-ACP in the chewing gum that they used (0.6\% in Trident White versus 10\% in MI Paste). The desensitising effect of Recaldent could be dose-related, and its 
concentration in the Trident White chewing gum might simply be too low to exert a noticeable difference. Future studies could better determine the true benefit of Recaldent by comparing MI Paste (containing 10\% CPP-ACP) with other traditional desensitising agents (such as fluoride varnish or potassium nitrate) that have some documented clinical efficacy.

\section{CONCLUSION}

Within the limits of this study, the following conclusions could be drawn:

1. In general, the Britesmile in-office tooth whitening procedure was effective in lightening the colour of teeth in a single treatment period of one hour. Most of our patients were also satisfied with their treatment outcomes

2. Chewing one piece of sugar-free gum (either with or without Recaldent) for 10 minutes every hour for 12 hours was found to significantly reduce the intensity of tooth sensitivity experienced by our patients. In the authors' opinion, the reduction in sensitivity was sufficiently large to imply clinical significance, suggesting that sugar-free chewing gum could be a useful adjunct for managing whitening-induced tooth sensitivity in the future

3. However, this study failed to demonstrate (with statistical significance) that using a chewing gum with Recaldent could provide more sensitivity relief than that of using a regular chewing gum. Yet it did not prove that CPP-ACP has no therapeutic benefits at all. Future studies with larger sample sizes and better experimental designs are needed to determine the true desensitising effect of this agent.

1. Feinman R A, Goldstein R E, Garber D A. Bleaching teeth. pp 10. Chicago: Quintessence, 1987.

2. Papathanasiou A, Kastali S, Perry R D, Kugel G.
Clinical evaluation of a 35\% hydrogen peroxide in-office whitening system. Compend Contin Educ Dent 2002; 23: 335-346.

3. Luk K, Tam L, Hubert M. Effect of light energy on peroxide tooth bleaching. J Am Dent Assoc 2004; 135: 194-201.

4. Patel A, Louca C, Millar B J. An in vitro comparison of current tooth whitening techniques on natural tooth colour. Br Dent J 2008; 204: E15.

5. Sulieman M, Addy M, MacDonald E, Rees J S. A safety study in-vitro for the effects of an in-office bleaching system on the integrity of enamel and dentine. J Dent 2004; 32: 581-590.

6. Yazici A R, Khanbodaghi A, Kugel G. Effects of an in-office bleaching system (Zoom) on pulp chamber temperature. J Contemp Dent Pract 2007; 8: 19-26.

7. Kugel G, Papathanasiou A Williams A J 3rd Anderson C, Ferreira S. Clinical evaluation of chemical and light-activated tooth whitening systems. Compend Contin Educ Dent 2006: 27: 54-62.

8. Tavares M, Stultz J, Newman M et al. Light augments tooth whitening with peroxide. J Am Dent Assoc 2003; 134: 167-175.

9. Lu A C, Margiotta A, Nathoo S A. In-office tooth whitening: current procedures. Compend Contin Educ Dent 2001; 22: 798-805.

10. Buchalla W, Attin T. External bleaching therapy with activation by heat, light or laser - a systematic review. Dent Mater 2007; 23: 586-596.

11. Haywood V B. A comparison of at-home and inoffice bleaching. Dent Today 2000; 19(4): 44-53.

12. Thitinanthapan $W$, Satmanont $P$, Vongsavan $N$. In vitro penetration of the pulp chamber by three brands of carbamide peroxide. J Esthet Dent 1999. 11: 259-264.

13. Addy M. Dentine hypersensitivity: new perspectives on an old problem. Int Dent J 2002; 52: 367-375.

14. Brannstrom M. A hydrodynamic mechanism in the transmission of pain producing stimuli through dentine. In Anderson DJ (ed) Sensory mechanisms in dentine. Proceedings of a symposium held at the Royal Society of Medicine, London, September 24th 1962. pp 73-79. Oxford, England: Pergamon Press, 1963.

15. Gaffar A. Treating hypersensitivity with fluoride varnishes. Compend Contin Educ Dent 1998; 19: 1088-1094.

16. Haywood V B, Cordero R, Wright K et al. Brushing with a potassium nitrate dentifrice to reduce bleaching sensitivity. J Clin Dent 2005; 16: 17-22.

17. Touyz L Z G, Stern J. Hypersensitive dentinal pain attenuation with potassium nitrate. Gen Dent 1999; 47: 42-45.

18. Cross K J, Hug N L, Reynolds E C. Casein phosphopeptides in oral health - chemistry and clinical applications. Curr Pharm Des 2007; 13: 793-800.

19. Rose R K. Binding characteristics of Streptococcus mutans for calcium and casein phosphopeptide. Caries Res 2000; 34: 427-431.

20. Reynolds E C. The use of casein phosphopeptides in oral care products for the prevention and treatment of early enamel caries. Aust J Diary Technol 2000; 55: $1-6$.

21. Walsh L J, Wang W S, Cakar A et al. Effect of CPP$A C P$ versus potassium nitrate on cervical dentinal hypersensitivity. J Dent Res 2006; 85(Spec Iss A): Abstract 947.

22. Shen P, Cai F, Nowicki A, Vincent J, Reynolds E C. Remineralization of enamel subsurface lesions by sugar-free chewing gum containing casein phosphopeptide-amorphous calcium phosphate. J Dent Res 2001; 80: 2066-2070.

23. Petrie A, Bulman J S, Osborn J F. Further statistics in dentistry part 4: clinical trials 2. Br Dent J 2002; 193: 557-561.

24. Petrie A, Bulman J S, Osborn J F. Further statistics in dentistry part 3: clinical trials 1. Br Dent J 2002; 193: 495-498.

25. Kugel G, Kastali S. Tooth-whitening efficacy and safety: a randomized and controlled clinical trial. Compend Contin Educ Dent Supp/ 2000; (29): S16-S21.

26. Haywood V B, Leonard R H, Nelson C F et al. Effectiveness, side effects and long-term status of nightguard vital bleaching. J Am Dent Assoc 1994; 125: 1219-1226.

27. Schulte J R, Morrissette D B, Gasior E J, Czajewski $M V$. The effects of bleaching application time on the dental pulp. J Am Dent Assoc 1994; 125: 1330-1335.

28. Sulieman M. An overview of bleaching techniques: 1. History, chemistry, safety and legal aspects. Dent Update 2004; 31: 608-616.

29. Jorgensen M G, Carroll W B. Incidence of tooth sensitivity after home whitening treatment. J Am Dent Assoc 2002; 133: 1076-1082.

30. Hewlett E R. Etiology and management of whitening-induced tooth hypersensitivity. J Calif Dent Assoc 2007; 35: 499-506.

31. Kingdon R T, Stanley K J, Kizior R J. Handbook for pain management. pp 28. Philadelphia: WB Saunders, 1998.

32. Tam L. Effect of potassium nitrate and fluoride on carbamide peroxide bleaching. Quintessence Int 2001; 32: 766-770.

33. Matis B A, Cochran M A, Eckert G J, Matis J I. In vivo study of two carbamide peroxide gels with different desensitizing agents. Oper Dent 2007; 32: 549-555.

34. Haywood V B, Caughman W F, Frazier K B, Myers M L. Tray delivery of potassium nitrate-fluoride to reduce bleaching sensitivity. Quintessence Int 2001; 32: 105-109.

35. Curro F A, Freedman M, Leight R S. Design and conduct of clinical trials on dentine hypersensitivity. In Addy M, Embery G, Edgar M W, Orchardson R (eds) Tooth wear and sensitivity: clinical advances in restorative dentistry. pp 299-314. London: Martin Dunitz, 2000.

36. Vaile J H, Davis P. Topical NSAIDs for musculoskeletal conditions. A review of the literature. Drugs 1998; 56: 783-799.

37. Fernandez $E_{1}$ Turk D C. The utility of cognitive coping strategies for altering pain perception: a meta-analysis. Pain 1989; 38: 123-135.

38. McCaul K D, Malott J M. Distraction and coping with pain. Psychol Bull 1984; 95: 516-533.

39. Stookey G K. The effect of saliva on dental caries. J Am Dent Assoc 2008; 139(Suppl): S11-S17.

40. Dawes $C$. Factors influencing salivary flow rate and composition. In Edgar M, Dawes C, O'Mullane D (eds) Saliva and oral health. 3rd ed. pp 32-49. London: British Dental Association, 2004.

41. Smeeton N. Dental statistics made easy. pp 48. Oxford: Radcliffe, 2005.

42. Marini I, Checchi L, Vecchiet F, Spiazzi L. Intraoral fluoride releasing device: a new clinical therapy for dentine sensitivity. J Periodontol 2000; 71: 90-95.

43. Schiff T, Zhang Y P, DeVizio W et al. A randomized clinical trial of the desensitizing efficacy of three dentifrices. Compend Contin Educ Dent Supp/ 2000; (27): S4-S10.

44. Pereira R, Chava V K. Efficacy of a 3 percent potassium nitrate desensitizing mouthwash in the treatment of dentinal hypersensitivity. J Periodontol 2001; 72: 1720-1725. 